\title{
POLYCYSCTIC OVARIAN SYNDROME (PCOS);
}

PREGNANCY RATE FOLLOWING OVULATION INDUCTION BY CLOMIPHENE ALONE AND WITH COMBINATION OF METFORMIN

\author{
Dr. Rashida Perveen', Dr. Sobia Hamid', Dr. Mehnaz Khakwani ${ }^{3}$
}

1. MBBS, FCPS (OBG)

Women Medical Officer Gynae Unit-I

Nishtar Hospital, Multan

2. MBBS, FCPS (OBG)

Women Medical Officer DHQ Khanewal

3. MBBS, FCPS (OBG)

Assistant Professor

Gynae Unit-I

Nishtar Hospital, Multan

Correspondence Address: Dr. Rashida Perveen MBBS, FCPS

Women Medical Officer Gyane Unit-1 Ward No. 16

Nishtar Hospital Multan.

drrashida83@hotmail.com

Article received on

10/10/2013

Accepted for Publication:

15/12/2013

Received after proof reading:

21/04/2014

\section{INTRODUCTION}

The polycystic ovary syndrome is the most prevalent endocrine disorder of women of reproductive age group affecting 5 to10\% of women $^{1}$ and may be the most common cause of female infertility ${ }^{2}$. Anovulation ${ }^{2}$, early pregnancy loss $^{3}$, and later pregnancy complications ${ }^{4}$. Obesity is also common in such ladies. The cause of polycystic ovary syndrome is not known.

Polycystic ovarian syndrome is characterized by two of the following three criteria.
1. Oligo-and/Oranovulation
2. Polycystic ovaries on ultrasound.

\begin{abstract}
Objective: To compare effectiveness of clomiphene alone and in combination with metformin in terms of conception rate in patients presenting with polycystic ovary syndrome. Design: Randomized clinical trail. Place and duration of study: Department Obstetrics Nishtar Hospital Multan, 6 months from 12th September 2009 to 11th Hospital Multan with significant irregular menstrual cycle, oligo menorrhea and ultrasonographic

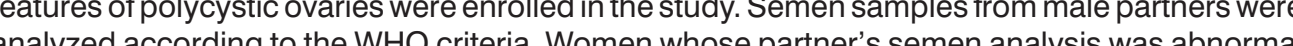
were excluded from study. Group 'A' was given clomiphene citrate alone and second group (i.e. ( (determined by history) ovulation by follicular tracking on ultrasonography, if patient (conceived), conception was confirmed by urine pregnancy test and inal sac on ultrasonography pelvis. Final outcome was measured at six month. . respectively. Oligomenorrhea was present in $18(50 \%)$ vs. $18(50 \%)$ women, amenorrhea in $7(19.4 \%)$ vs. $8(22.2 \%)$ patients and weight gain in $14(38.9 \%)$ vs. $15(41.7 \%)$ cases in group $A$ and respectively. Conclusions: Metformin does not seem to help in achieving higher rates of 列
\end{abstract}

Article Citation: Parveen R, Hamid S, Khakwani M. Polycysctic ovarian syndrome (PCOS); pregnancy rate following ovulation induction by clomiphene alone and with combination of metformin. Professional Med J 2014;21 (2): 354-359. 
successful in ovulation induction in $80 \%$ of cases $^{7}$.

Because of the link between insulin resistance and PCOS metformin has been put forward as a drug to induce ovulation in women with $\mathrm{PCOS}^{8}$. As insulin resistance seems to be a key feature in PCOS increase in serum concentration of insulin is common in both lean and obese women with PCOS. Insulin stimulates androgen secretions by ovarian stoma and affects normal development of ovarian follicles. Insulin also leads to suppression of liver production of sex hormone binding globulin and increases free androgens ${ }^{9}$.

Metformin inhibits production of hepatic glucose and thereby decreases insulin secretion so can be used to treat hyperinsulinemia in $\mathrm{PCOS}^{10}$.

Surgical methods include wedge resection used previously. It is to be condemned as it is the operation that is associated with destruction of already diseased ovaries and might transfer the patient from ovulatory problem to ovulatory and tubal problem because of post operation adhesions $^{11}$.

Laproscopic ovarian drilling is being frequently performed for ovulation induction but requires Laparoscopic surgical instruments, not available in most hospitals therefore most doctors lack experience and skill in performing Laparoscopic surgery. This surgical procedure is associated with its own risks. On the other hand, females of low income group are unable to affored this procedure in private hospital.

\section{METHODOLOGY}

This randomized clinical trail was carried out in Department of Obstetrics and Gynaecology Unit I, Nishtar Hospital Multan. Over a period of 6 months from 12th September 2009 11th March 2010 Non probability purposive sampling technique was used to select 72 patients.

Inclusion criteria included

1. Age less than 35 years

2. Infertility: Primary

3. Oligo or amenorrhoea.
4. Polycystic ovaries on pelvic or transvaginal ultrasound.

5. Normal semen analysis according to $\mathrm{WHO}$ 1999 criteria.

\section{Exclusion Criteria included}

- All other endocrinological causes of female infertility including congenital adrenal hyperplasia, Cushing's Syndrome, hyperprolactinemia and thyroid disease.

Information about age, weight, duration of infertility, former pregnancies, and menstrual cycle patterns were obtained and previous infection. Contraception and consumption of medicine for infertility treatment were recorded.

Informed consent was taken by explaining risks/benefits of the medicines to the patient as well as her husband. Approval of Hospital Ethical Committee was sought.

Required number of chits (i.e 72) were made $50 \%$ were marked as ' $A$ ' and the rest with ' $B$ '. Patients were asked to pick one slip when consenting for treatment. In this way two groups were made.

Group 'A' was given clomiphene citrate alone and second group (i.e group B) was given clomiphene citrate and metformin according to following regimens.

The patients were given clomiphene $50 \mathrm{mg}$ once daily for 5 days started from second day of menstrual cycle upto three cycles.

Metformin $500 \mathrm{mg}$ three times a day was given. The dose was gradually increased over a period of 3 weeks to achieve required dose. All patients were followed till six cycles for regularity of menstrual cycle (determined by history) and ovulation by follicular tracking on ultrasonography (dominant follicle on day 12 and absent follicle on day 16. If patient missed the cycle (conceived), conception was confirmed by urine pregnancy test and gestational sac on ultrasonography pelvis. Final outcome was measured at six month. 
This information was entered in proforma specifically designed for the study (attached as annexure).

Data were entered and analyzed using computer programme SPSS-10 to find out frequencies and percentages of outcome variables like conception rate. P-value equal or less than 0.05 was considered as significant.

\section{RESULTS}

Total number of patients during study period was 2135, out of which 300 had PCOS, so frequency of PCOS was $14.05 \%$. For age wise distribution of patients with PCOS, $3(8.3 \%)$ in group $A$ and $4(11.1 \%)$ patients in group $B$ were between $21-25$ years, $14(38.9 \%)$ vs. $14(38.9 \%)$ patients were between 26-30 years in group $A$ and $B$ respectively, while $19(52.8 \%)$ vs. $18(50.0 \%)$ patient were between 31-35 years in group $A$ and $B$ respectively. The means age of the patients was $31.03 \pm 058$ vs. $2989 \pm 0.53$ years in group $A$ and $B$ respectively. Age of the patients ranged from 2135 years (Table No. I \& II).

Regular menstrual cycle was observed in $11(30.6 \%)$ vs. $10(27.8 \%)$ in group $A$ and $B$ respectively. Menstrual irregulatrities were most common clinical presentation. Oligomenorrhea was present in $18(50 \%)$ vs. $18(50 \%)$ women in group $A$ and $B$ respectively, amenorrhea in $7(19.4 \%)$ vs. $8(22.2 \%)$ patients in group $A$ and $B$ respectively, and weight gain in $14(38.9 \%)$ vs. $15(41.7 \%)$ cases in group $A$ and $B$ respectively. Hirsutism was less common present among 4 $(11.1 \%)$ vs. $3(8.3 \%)$ cases respectively in group $A$ and $\mathrm{B}$.

Raised serum LH, FSH, prolactin and testosterone were evident in $26(72.2 \%)$ vs. $27(75 \%), 13(36.1 \%)$ vs. $21(58.3 \%), 4(11.1 \%)$ vs. $5(13.9 \%)$ and $7(19.4 \%)$ vs. $9(25 \%)$ cases in group $A$ and $B$ respectively.

Conception was achieved in $26(72.2 \%)$ vs. 18(50.0\%) patients in group $A$ and $B$ respectively as show in Table No. III.

\begin{tabular}{|c|c|c|}
\hline \multirow{2}{*}{ Age (in years) } & \multicolumn{2}{|c|}{ No. of patients } \\
\hline & Group A (n=36) & Group B (n=36) \\
\hline $21-25$ & $3(8.3 \%)$ & $4(11.1 \%)$ \\
\hline $26-30$ & $14(38.9 \%)$ & $14(38.9 \%)$ \\
\hline $31-35$ & $19(52.8 \%)$ & $18(50.0 \%)$ \\
\hline
\end{tabular}

Table-I. Age-Wise Distribution of Patients with PCOS

Key: $P C O S=$ polycystic ovary syndrome.

Group $A=$ Patients given clomiphene citrate alone.

Group $B=$ Patients given clomiphene citrate and metformin.

\begin{tabular}{|l|c|c|}
\hline \multicolumn{1}{|c|}{$\begin{array}{c}\text { Variable } \\
\text { (Mean } \pm \text { S.E.M) }\end{array}$} & \multicolumn{2}{|c|}{ No. of patients } \\
\hline Age (in years) & $31.03 \pm 0.58$ & $29.89 \pm 0.53$ \\
\hline $\begin{array}{l}\text { Serum FSH J } \\
\text { (IU/L) }\end{array}$ & $9.61 \pm 0.40$ & $10.58 \pm 0.34$ \\
\hline $\begin{array}{l}\text { Serum LH J } \\
\text { (IU/L) }\end{array}$ & $12.53 \pm 0.51$ & $12.58 \pm 0.40$ \\
\hline $\begin{array}{l}\text { Serum Prolactin } \\
\text { (mIU/L) }\end{array}$ & $350.11 \pm 7.94$ & $322.89 \pm 10.31$ \\
\hline $\begin{array}{l}\text { Serum } \\
\text { testosterone } \\
\text { (nmol/L) }\end{array}$ & $2.56 \pm 0.16$ & $2.67 \pm 0.16$ \\
\hline \multicolumn{2}{|c|}{ Table-II. Descriptive Statistics } \\
\hline Youp
\end{tabular}

\section{DISCUSSION}

Polycystic ovary syndrome is a common reproductive disorder associated with many characteristic features, including hyperandrogensim, insulin resistance and obesity which may have significant implications for pregnancy outcomes and long-term health of the woman.

Clomiphene citrate was the first agent used in experiments for ovulation induction in 
oligomenorrhic women $^{12}$. For many years it was and may still be the first therapeutic option managing anovulatory infertility. The treatment with clomiphene citrate in anovulatory PCOS women is associated with an ovulation rate of $60-$ $85 \%$ \& pregnancy rate of $30-40 \%{ }^{13}$. The effect of metformin in combination to clomiphene citrate has been evaluated in a number of studies. Some studies has found a significant benefit while the others did not. However the addition of metformin to clomiphene citrate in clomiphene citrateresistant women significantly improves the ovulation rate. A meta analysis in a Cochrane review reported a significant benefit for metformin compared to placebo for ovulation in anovulatory women with $\mathrm{PCOS}^{14}$. Another meta analysis showed a significant positive effect of metformin when added to clomiphene citrate in the clomiphene citrate-resistant PCOS patient ${ }^{15}$.

Present study was carried out to compare effectiveness of clomiphene alone and in combination with metformin in terms of conception rate in PCOS patients. In our study, oligomenorrhea was present in $50 \%$ of the patients in each group followed by amenorrhea in $19.4 \%$ vs. $22.2 \%$ patients in the two groups and weight gain in $38.9 \%$ vs. $41.7 \%$ patients in Group A and B respectively.

Ayisha Raja and colleagues $^{16}$ have reported oligomenorrhea in $52 \%$ vs. $64 \%$ patients, dysmentorrhea in $52 \%$ vs. $56 \%$ cases and hirsuitism in $64 \%$ vs. $66 \%$ patients in metformin + $\mathrm{CC}$ and $\mathrm{CC}$ only groups respectively.

In a study carried out by Fauiza et $\mathrm{al}^{17}$ in Pakistani patients oligomenorrhea was found in $75 \%$ of their cases. In the same study, hirsuitism was found in $84.6 \%$ of cases which is quite high.

Fouzia Kashif et $\mathrm{al}^{18}$ have mentioned in their study $81 \%$ cases had history or mensutral irregularity and in $72 \%$ women hirsuitism was seen, while history of weight gain was present in $62 \%$ of the patients.

In present study, in group B patient (given clomiphene citrate in combination with metformin) pregnancy could be achieved in $18(50.0 \%)$ cases while in group $A$ (give clomiphene citrate alone) conception was achieved in $26(72.2 \%)$ cases. A number of studies have similar findings negating the role of metformin when combine with clomiphene citrate in achieving conception.

In the study by Neveu et $\mathrm{al}^{19}$ they prospectively randomized 154 patients with PCOS. Pregnancy rates were equivalent in the three groups (clomiphene citrate, metformin, or the combination of both). They also observed a better ovulatroy response in the women with a lower BMI in the clomiphene citrate group and patients with a BMI of 27-35 responded better to metformin for ovulation induction. The mean BMI of the study was 31 . This study had a better ovulation rate in the metformin group and the combination group (CC + Metformin) $(P=0.005)$, but no difference in pregnancy rates between the three groups $(P=0.332)$. This study concluded that it is not beneficial to add metformin to clomiphene citrate in primary ovulation induction protocols.

In a study by Legro et al, ${ }^{20} 626$ PCOS patients were randomized. The primary outcome of their study was live birth rates. They concluded that clomiphene citrate $(22.5 \%)$ is superior to metformin $(7.2 \%)$ but similar to the combination group (26.8\%) in achieving live birth rates. The conception rate among subjects who ovulated was significantly lower in the metformin group $(21.7 \%)$ than in either the clomiphene group (39.5\%, $\mathrm{P}=0.002)$ or the combination-therepy group (46.0\%, $\mathrm{P}<0.001)$. They did not observe any difference in the abortion rates between the three groups and observed a significantly better live birth rate if the $\mathrm{BMI}$ is less than 30 regardless of the treatment options used. Conception, pregnancy, and live birth were significantly more likely to occur after treatment with clomiphene alone than after metformin alone. They supported the use of clomiphene citrate alone as first-line therapy for infertility in women with the polycystic ovary syndrome.

Palomba $S$ et $\mathrm{al}^{21}$ in a recent systematic review of head-to-head randomized controlled studies 
observed no difference in fertility improvement comparing $\mathrm{CC}$ with metformin $(\mathrm{OR}=1.22,95 \% \mathrm{Cl}$ $0.23-6.55 \mathrm{P}=0.815)$. Homogeneous data showed no difference in fertility improvement between the combination treatment and CC monotherapy (OR $=0.99,95 \% \mathrm{Cl} 0.70-1.40, \mathrm{P}=0.982)$. They concluded that in PCOS patients with anovulatroy infertility and not previously treated, the administration of metformin plus CC is not better than monotherapy (metformin alone or CC alone).

Safdar Ali Malik et $\mathrm{al}^{22}$ have ovulation rates as high as $75 \%$ patients while pregnancy was achieved in $58 \%$ of patients while treated with clomiphene citrate alone.

In a recent multi-center randomized trail ${ }^{23} \mathrm{CC}$ proved to be superior to metformin. Clinical pregnancy rate were $40 \%$ with metformin $39 \%$ with CC, $54 \%$ with combination metformin plus CC.

However a number of studies carried out establishing a role of metformin in achieving pregnancy when combined with CC. Ayisha Raja ${ }^{16}$ Tang T et $\mathrm{al}^{25}$ Creanga et $\mathrm{al}^{26}{ }^{26}$ were of this opinion and favoured use of metformin.

Our study is a single center study with a small smaple size, so results cannot be generalized. Large randomized clinical trails are required to further investigate the role of metformin in achieving conception in PCOS women.

\section{CONCLUSIONS}

Conception rate $72.2 \%$ with Clomiphene Citrate alone and $50.0 \%$ when metformin is combined suggest that metformin does not have a role in achieving higher rates of pregnancy. Role of metformin is therefore controversial.

Copyright(C) 15 Dec, 2013.

\section{REFERENCES}

1. Knochenhauer ES, Key TJ, Kahsar-Miller M. Waggoner W, Boots LR, Azziz R. Prevalence of the polycystic ovary syndrome in ulselected black and white women of the Southeastern United States: a prospective study, J Clin Endocrinol Metab 1998;83:3078-82.

2. Hull MG. Epidemiologyy of infertility and polycystic ovarian disease: endocrinological and demographic studies. Gynecol Endocrinol. 1987;1:325-45.

3. Homberg R, Armar NA, Eshel A, Adams J, Jacobs $H S$. influence of serum luteinizing hormone concentrations on ovulation conception and early pregnancy loss in polycystic ovary syndrome BMJ. 1998; 297:1024-6.

4. Boomsma CM, Eijkemans MJ, Hughes EG, Visser $\mathrm{GH}$, Fauser BC, Macklon NS. A meta-analysis of pregnancy outcomes in women with polycystic ovary syndrome. Hum Reprod Update. 2006;12:673-83.

5. Nestler JE, Jakubowicz DJ, Evans WS, Pasqeali R. Effect of metaformin on spontaneous and clomiphene-induced ovulation $\mathbf{n}$ the polycystic ovary syndrome. N Engl J Med. 1999;340:1314-20.

6. Practice Committee of American Society for Reproductive Medicine. Use of clomiphene citrate in women. Fertil Steril 2003;80:1302-8.

7. Imani B, Eijkemans MJ, te Velde ER, Habbena JD, Fauser BC. A nomogram to predict the probability of live birth after clomiphene citrate induction of ovulation in normogonadotrophic oligoamenorrheic infertility. Fertil Steril. 2002;77:91-7.

8. El-biely MM, Habba M. The use of metformin to augment the induction of ovulation in obese infertile patients with polycystic ovarian syndrome. Middle East Fertil Soc J. 2001;6:43-9.

9. Balen A. PCOS. In Shaw RW, Soutter WP, Stanton SL, editors. Gynaecology. Edinburgh: Churchill Livingstome; 2003. p. 259-70.

10. Checa MA, Requena A, Slavador C, Tur R, Callejo J, Espinos JJ, et al. Insulin sensitizing agents; use in pregnancy and as therapy in PCOS. Hum Reported updates. 2005;11:375-90.

11. Lotfi G. Polycystic ovarian disease: treatment protocols. [Online]. 2005 [cited 2008 March 07]; Available from: URL: http://www.obgyn.net/pcos/ pcos.asp?page $=/$ pcos/articles/lotfi-pcos-procols. htm.

12. Holtkamp DE, Greslin JG, Root CA, Lerner LJ, Gonadotorpin inhibiting and anti-fecundity effects of chloramiphene. Proc Soc Exp Biol Med. 1960;105:197-201.

13. Hughes E, Collins J, Vanderkerckhove P, Lilford R. Clomiphene citrate for ovulation induction in women with oligo-amenorrhoea. Cochrane 
Database Syst Rev. 2000; CD000056.

14. Lord JM, Flight IHK, Norman RJ, Metformin in polycystic ovary syndrome: systematic review and meta-analysis. BMJ. 2003;;;327:951-6.

15. Siebert IT, Kruger TF, steyn DW, Nosarka S. Is the addition of metformin efficacious in the treatement of clomiphene citrateresistant patients with polycystic ovary syndrome? A structures literature review. Fertil Steril. 2006;86:1432-7.

16. Raja A, Hashmi SN, Sultana $\mathrm{N}$, Rashid $\mathrm{H}$. Presentations of polycystic ovary syndrome and its management with Clomiphene alone and in combination with metformin. J Ayub Med Coll Abbottabad. 2005;17(2):50-3.

17. Fauzia N, Shagufta S, Maryum M, Huma A, Saadat A, Saad R. Polycystic ovary syndrome-diagnosis and management in fertility deprivation. Pak $\mathrm{J}$ obstet Gynacol. 1999;12(1,2):59-71.

18. Kashif F, Abro ST, Bhatti A, Laghari I, Baloch R. Clinical diagnosis of poly cystic ovarian syndrome and response to metformin therapy in respective of menstrual irregularitiesand conception rate. Med Channel. 2010;16(10):14951.

19. Neveu N, Granger L, St-Michel P, Lavoie HB. Comparison of clomiphene citrate, metaformin, or the combination of both for first-lineovulation induction and achievement of pregnancy in 154 women with polycystic ovary syndrome. Fertile Steril. 2007;87:113-20.

20. Legro RS, Baranhart HX, Schiaff WD, Carr BR, Diamond MP, Carson SA, et al. Clomiphene, metformin, or both for infertility in the polycystic ovary syndrome. N Engl J Med. 2007;356:551-66.

21. Palomba S, Pasquali R, Orio F Jr, Nestler JE. Clomiphene citrate, metformin or both as firststepapproach in trating anovulatory infertility in patients with polycystc ovary syndrome (PCOS): a systematic review of head-to-head randomized controlled studies and meta-analysis. Clin Endocrinol (Oxf). 2009;70(2):311-21.

22. Malik SA, Khanum Z, Yousuf KR, Asif S. Prevalence of polycystic ovarian syndrome in infertility (PCOS) and treatment with clomiphene citrate. Ann King Edward Med Coll. 2001;7(1):8-10.

23. Johnson NP, Stewart AW, Falkiner J, Farquhar CM, Milsom S, Singh VP, et al. PCOSMIC: a multi-centre randomized trail in women with polycystic ovary syndrome evaluating metformin for infertility with clomiphene. Hum Reprod. 2010 [Epub a head of print].

24. Raja A, Hashmi SN, Sultana N, Rashid $H$. Presentations of polycystic ovary syndrome and its management with Clomiphene alone and in combination with metformin. J Ayub Med Coll Abbottabad. 2005;17(2):50-3.

25. Tang T, Lord JM, Norman RJ, Yasmin E, Balen AH. Insulin-sensitising drugs (metformin, rosiglitazone, pioglitazone, D-chiro-inosiotol) for women with polycystic ovary syndrome, oligo amenorrhea and subfertility. Cochrane Database Syst Rev. 2010;(1):CD003053.

26. Creanga AA, Bradley HM, McCormick C, Witkop CT. Use of metformin in polysystic ovary syndrome: a meta-analysis. Obstet Gynecol. 2008;111(4):95968. 